\title{
Nutrient enrichment affects recruitment of oysters and barnacles in a mangrove forest
}

\author{
Todd E. Minchinton ${ }^{1, *}$, Louise A. McKenzie ${ }^{1,2}$ \\ ${ }^{1}$ Institute for Conservation Biology and School of Biological Sciences, University of Wollongong, \\ New South Wales 2522, Australia \\ ${ }^{2}$ Present address: School of Biological, Earth and Environmental Sciences, University of New South Wales, \\ New South Wales 2052, Australia
}

\begin{abstract}
We tested the hypothesis that nutrient enrichment affects recruitment of the oyster Saccostrea glomerata and the barnacle Hexaminius popeiana, which are dominant occupiers of space on tree trunks in temperate mangrove forests in New South Wales, Australia. We measured recruitment on artificial settlement plates at high and low intertidal levels under ambient conditions and where we manipulated nutrient levels by adding fertiliser to the water column for 2 mo. To determine whether nutrients influenced temporal patterns of settlement and early mortality of larvae, we quantified recruitment for 2 sampling intervals: on plates that were replaced 4 times at 2 wk intervals and on those left in the field for the entire 2 mo. For both intervals, recruitment of oysters was 3 to 4 times and significantly higher under elevated than ambient nutrient conditions. Recruitment of barnacles was also significantly higher under elevated nutrient conditions, but only on plates sampled at $2 \mathrm{wk}$ intervals. On plates left out for $2 \mathrm{mo}$, the effect of nutrients on recruitment was variable, but recruits were generally higher in number under ambient conditions, suggesting that nutrients might enhance postsettlement mortality. Nutrient enrichment clearly affected recruitment of oysters and barnacles, possibly by mimicking natural settlement cues of conspecific individuals. Considering the central role of recruitment to the population dynamics of marine benthic invertebrates, nutrient enrichment has the potential to alter species assemblages in estuarine and marine habitats.
\end{abstract}

KEY WORDS: Larval settlement · Postsettlement mortality · Gregarious settlement behaviour • Nitrogen $\cdot$ Phosphorus $\cdot$ Eutrophication $\cdot$ Substratum type $\cdot$ Estuaries

\section{INTRODUCTION}

Across the globe, humans are increasingly subjecting coastal and estuarine waters to chronic nutrient enrichment (Carpenter et al. 1998). For example, terrestrial runoff containing fertilisers and sewage has augmented the supply and facilitated the transfer of nutrients to nearshore waters (Valiela et al. 1997). Increased nutrient load to coastal habitats naturally limited by key elements, such as nitrogen and phosphorus (Valiela \& Teal 1974, Boto \& Wellington 1983, Clarke 1985), may alter and have important consequences for the behavioural, demographic and ecological processes that govern the dynamics of marine populations. Indeed, studies in a range of coastal habitats demonstrate that variations in nutrient levels can significantly influence the structure and species diversity of marine communities (e.g. intertidal rocky shores, Littler \& Murray 1975; subtidal rocky reefs, Russell \& Connell 2005; coral reefs, McClanahan et al. 2002; intertidal soft sediments, Morris \& Keough 2003; salt marshes, Minchinton \& Bertness 2003).

Recruitment, or the addition of juveniles to a population, is a fundamental demographic process affecting the dynamics of populations and interactions among species in marine benthic habitats (Minchinton \& Scheibling 1991, Caley et al. 1996). For most marine benthic invertebrates, recruitment is a function of the supply, settlement and early postsettlement mortality of larvae (Keough \& Downes 1982). Larvae are sensi- 
tive organisms with complex behaviours, relying on physical, chemical and biological cues to determine where they take up residence in the benthic habitat (Burke 1983, Pawlik 1992). Consequently, changes to the benthic and pelagic environment resulting from nutrient enrichment of coastal waters could influence the settlement and early survival of larvae by altering settlement cues or conditions for successful metamorphosis and growth in the benthic habitat (Koop et al. 2001, Jara et al. 2006).

There have been relatively few direct, experimental tests in the field examining the response of invertebrate larvae to nutrient manipulations (e.g. Renaud et al. 1999, Koop et al. 2001). Investigations in the field and laboratory indicate, however, that nutrients can influence recruitment, but that the response varies among taxa. For example, elevated nutrient levels have been shown to reduce settlement of the corals Diploria strigosa (Bassim \& Sammarco 2003) and Acropora longicyathus (Ward \& Harrison 1997), to enhance settlement of the oysters Crassostrea virginica and $C$. gigas (Coon et al. 1990, Fitt \& Coon 1992), and to have no effect on recruitment of the coral Pocillopora damicornis (Cox \& Ward 2002). Considering the central role of recruitment in the population dynamics of marine benthic invertebrates, nutrient enrichment has the potential to affect dramatically species assemblages in estuarine and marine habitats.

In the present study we tested the hypothesis that nutrient enrichment affects recruitment of the oyster Saccostrea glomerata and the barnacle Hexaminius popeiana, which are both common and abundant species that dominate space on trees in the intertidal zone of temperate mangrove forests in New South Wales, Australia (Ross \& Underwood 1997, Minchinton \& Ross 1999). Although mangrove forests occupy the interface between marine and terrestrial environments, intercepting anthropogenic sources of nutrients, the influence of nutrient enrichment on invertebrate recruitment in this habitat has not received attention. In this study, we manipulated nutrient levels surrounding artificial settlement plates placed along the seaward edge of a mangrove forest and then monitored recruitment of oysters and barnacles under ambient and elevated nutrient conditions for 2 mo. We also wanted to refine previous field studies by examining the influence of nutrients on the various components of recruitment, and thus determine whether the initial response of larvae to nutrients at settlement would reflect longer-term patterns of recruitment. We did this by quantifying recruitment for 2 sampling intervals: on plates replaced 4 times at 2 wk intervals and on plates left in the field for the entire 2 mo. Recruitment on plates left out for 2 mo integrated the settlement response of larvae to nutrients in the presence of a developing assemblage of benthic species on the plates, as well as early mortality of recent settlers, whereas recruitment on plates replaced at $2 \mathrm{wk}$ intervals more directly reflected the pure settlement response of larvae to nutrients (Minchinton \& Scheibling 1993a).

\section{MATERIALS AND METHODS}

Study locations. The study was conducted from midto late summer 2005 in the temperate mangrove forest at Woolooware Bay in Botany Bay $\left(34^{\circ} 01^{\prime} \mathrm{S}\right.$, $\left.151^{\circ} 09^{\prime} \mathrm{E}\right)$, about $18 \mathrm{~km}$ south of Sydney, New South Wales, Australia. Mangrove forests at this latitude are comprised of 2 species: the tree Avicennia marina, which dominates throughout the forest, and the smaller shrub Aegiceras corniculatum, which typically occupies more landward areas of the forest. The mangrove forest is bordered by mudflats and seagrasses on its seaward side and by salt marshes on its landward side. The study was performed along the seaward edge of the forest, which is dominated by $A$. marina. The oyster Saccostrea glomerata dominates space on the trunks of $A$. marina at low tidal levels, while the barnacles Elminius covertus and Hexaminius popeiana dominate at high tidal levels (Ross \& Underwood 1997, Minchinton \& Ross 1999). Tides are semidiurnal with a maximal tidal range of about $2 \mathrm{~m}$.

Experimental design. Forty collectors with plates attached for the settlement of oyster and barnacle larvae were placed along the seaward edge of the forest in an area extending $200 \mathrm{~m}$ alongshore and $5 \mathrm{~m}$ into the forest. To maximize recruitment and minimize damage by flotsam, collectors were individually positioned on the landward side and within $1 \mathrm{~m}$ of mangrove trees. Each collector was separated by at least $5 \mathrm{~m}$ and randomly assigned to 1 of 4 treatment combinations ( $\mathrm{n}=10$ collectors per treatment) constituting 2 factors in an orthogonal design: sampling interval ( 2 wk or $2 \mathrm{mo}$ ) and nutrients (ambient or elevated). 'Sampling interval' consisted of 4 intervals of $2 \mathrm{wk}$ or 1 interval of $2 \mathrm{mo}$, respectively, over the same 2 mo period from the beginning of January 2005 to the beginning of March 2005. For collectors sampled at 2 wk intervals, plates were replaced at the end of each 2 wk interval. To maximize recruitment, collectors were placed in the field during neap tides so that they spanned periods of new or full moons (Ross 1993). Sampling was done at this time of the year because it is a known time of recruitment for Saccostrea glomerata and Hexaminius popeiana (Underwood \& Anderson 1994, Ross 1996, 2001). There are outstanding taxonomic issues about whether $H$. popeiana is 1 species or 2, and we follow the advice of Ross (1996) and con- 
sider all recruits of Hexaminius as $H$. popeiana (see Ross 1996 and references therein).

Collectors consisted of a $60 \mathrm{~cm}$ wooden stake with two $30 \mathrm{~cm}$ wooden crossbars, one attached at $30 \mathrm{~cm}$ and one at $60 \mathrm{~cm}$. Two plates (1 PVC, 1 wood) spaced $20 \mathrm{~cm}$ apart were attached with cable ties to the upper crossbar and 1 plate (PVC) to the lower crossbar. Different plate materials and tidal levels were purposefully chosen to maximize opportunities for recruitment (specifically PVC at low tidal levels for Saccostrea glomerata and wood at high tidal levels for Hexaminius popeiana), but it was not the objective of this study to compare these differences statistically. Wood plates were $15 \times 10 \times 1.7 \mathrm{~cm}$, giving top and bottom areas of $150 \mathrm{~cm}^{2}$ and side areas of $85 \mathrm{~cm}^{2}$. Plates made of PVC were $25 \times 7.2 \mathrm{~cm}$, giving top and bottom areas of $180 \mathrm{~cm}^{2}$. The PVC material is used by oyster farmers in the region for collecting oyster spat and is textured with shallow, longitudinal grooves. Plates were oriented parallel to the substratum, and the PVC plates, which were curved, were attached to collectors with their concave sides facing down. Plates were soaked in water for about $2 \mathrm{wk}$ before placing them in the field. Collectors were stuck into the mud to a depth of $15 \mathrm{~cm}$ so that the plate on the lower crossbar was at a height of $15 \mathrm{~cm}$ above the substratum and the 2 plates on the upper crossbar at a height of $45 \mathrm{~cm}$ above the substratum. Therefore, plates on the lower crossbar were at low tidal levels occupied by the oyster $S$. glomerata and plates attached to the upper crossbar were at high tidal levels occupied by the barnacle $H$. popeiana.

Nutrient levels were elevated by attaching perforated (fourteen $1 \mathrm{~mm}$ diameter holes), plastic centrifuge tubes $(10 \mathrm{ml})$ filled with $10 \mathrm{~g}$ of Osmocote ${ }^{\circledR}$ slow-release fertiliser to each of the plates (see also Hall et al. 2000). The fertiliser contained N:P:K in a ratio of $27: 1.3: 3.3$, including $27 \% \mathrm{~N}$ (5.3\% ammoniacal $\mathrm{N}, 11.8 \%$ urea $\mathrm{N}, 9.8 \%$ slow release N), $1.3 \% \mathrm{P}(1.0 \%$ water soluble, $0.3 \%$ citrate soluble), and $3.3 \% \mathrm{~K}(3.3 \%$ water soluble chloride free $\mathrm{K}$ ), as well as $8 \%$ sulphur, $2 \%$ iron, and $1 \%$ manganese. We used this type and these relatively high levels of fertiliser so that nutrients would be gradually released over time and to simulate the cocktail of nutrients that might be expected to run off from urbanised catchments through outfalls and thus enrich adjacent coastal waters (Sydney Water Corporation 2005). Importantly, although we label these chemical compounds as nutrients throughout the study, we recognise that any effects on invertebrate recruitment might have nothing to do with the nutritive properties of these compounds per se.

Three centrifuge tubes were attached with cable ties and hung directly beneath each plate without covering the area for settlement, supplying a total of $30 \mathrm{~g}$ of fertiliser per plate or $90 \mathrm{~g}$ per collector. Nutrients were placed beneath the plates because oysters and barnacles are typically at their greatest densities on the undersides of trunks of trees, and thus we anticipated that most larvae would settle on the bottoms of plates (Minchinton \& Ross 1999, Ross 2001). Fertiliser dissolved during flood tides, and nutrients were released into the water through the holes drilled into each centrifuge tube. A pilot study in the laboratory, where tubes with fertiliser were placed in beakers under still water and natural light conditions, indicated that all nutrients would be dissolved in about 14 to $18 \mathrm{~d}$, given the expected submersion times of tubes by the tides (tubes were largely protected from the rain by the plates and trees). Detailed observations in the field indicated that fertiliser dissolved at a steady rate, but occasionally nutrients were exhausted in less than 14 d. Nevertheless, on average, collectors with fertiliser received more nutrients than those under ambient conditions (see 'Results'). Plates receiving nutrients were replenished every 2 wk by attaching new centrifuge tubes filled with fresh fertiliser. To control for any effects associated with the presence and replacement of the centrifuge tubes, unperforated centrifuge tubes filled with seawater were similarly attached beneath plates under ambient nutrient conditions, and these tubes were also replaced every $2 \mathrm{wk}$.

Nutrient analysis. To determine the efficacy of fertiliser addition on the nutrient environment that larvae would experience in the water surrounding the collectors, on one day in March 2005, water was sampled adjacent to 4 collectors with fertiliser addition and 4 with no fertiliser. Sampling was done on the second high tide after fertiliser addition. Water was sampled about $5 \mathrm{~cm}$ beneath the plates at high tidal levels by submerging a $250 \mathrm{ml}$ sealed, acid-washed high-density polyethylene (HDPE) bottle which was opened and resealed underwater. Water samples were immediately placed on ice, transported to the laboratory and, within $3 \mathrm{~h}$ of collection, were filtered through a $0.45 \mu \mathrm{m}$ membrane filter into HDPE bottles and frozen. Concentrations of phosphorus (orthophosphates) and nitrogen (nitrates, nitrites, and ammonia) in the water were analysed by Southern Cross Laboratories (Sydney, Australia) within 1 mo of collection according to methods of the American Public Health Association (1998). A standard solution of nutrients analysed at the same time was within 3.9, 2.5 and $1.8 \%$ of known concentrations for orthophosphates, nitrates and ammonia, respectively. Nutrient concentrations that were below levels of reliable detection $\left(<5 \mu \mathrm{g} \mathrm{l}^{-1} \mathrm{~N}\right.$ or P) were assigned a value of $5 \mu \mathrm{g} \mathrm{l^{-1 }}$ for statistical analyses.

Data and statistical analysis. Recruits were counted on all surfaces (tops and bottoms, and also sides for wood) of the plates using a dissecting microscope. Because nutri- 
ents were placed beneath the plates, however, we here restrict our graphical presentation and statistical analyses of results to recruitment on the bottoms of plates. The density of oyster and barnacle recruits on plates for the four $2 \mathrm{wk}$ intervals was estimated as the sum of the number of individuals on each of the 4 plates, and for the one 2 mo interval as the number of individuals on plates at the end of the 2 mo interval. Densities were standardised per $100 \mathrm{~cm}^{2}$ for graphical presentation and statistical analysis. Several plates were lost or damaged, leaving 7 replicates per treatment. Recruit densities were analysed using 2-factor ANOVA (sampling interval and nutrients as fixed factors) after transformation to their natural logarithms to homogenise variances. Differences in nutrient concentrations in the water under ambient and elevated conditions were analysed using MannWhitney $U$-tests on untransformed data.

\section{RESULTS}

Experimental addition of fertiliser successfully increased the concentrations of phosphorus and nitrogen in the water column. Concentrations of orthophosphate, nitrate, and ammonia under elevated nutrient conditions $\left(4.5 \pm 1.57 \mu \mathrm{mol} \mathrm{l}^{-1} \mathrm{PO}_{4}-\mathrm{P}, 1.3 \pm 0.40 \mu \mathrm{mol} \mathrm{l}^{-1}\right.$ $\mathrm{NO}_{3}-\mathrm{N}$, and $183.1 \pm 64.2 \mu \mathrm{mol} \mathrm{l} \mathrm{l}^{-1} \mathrm{NH}_{3}-\mathrm{N}_{i}$ mean $\pm \mathrm{SE}$ ) were, respectively, 25.9, 3.2, and 250.1 times and significantly higher than those under ambient conditions $\left(0.17 \pm 0.012 \mu \mathrm{mol} \mathrm{l}^{-1} \mathrm{PO}_{4}-\mathrm{P}, 0.41 \pm 0.054 \mu \mathrm{mol} \mathrm{l}^{-1} \mathrm{NO}_{3}{ }^{-}\right.$ $\mathrm{N}$, and $0.73 \pm 0.221 \mu \mathrm{mol} \mathrm{l}^{-1} \mathrm{NH}_{3}-\mathrm{N}_{\text {; }}$ mean $\pm \mathrm{SE}_{\text {; Mann- }}$ Whitney $U$-tests, $\mathrm{p}<0.05$ for each). For all samples, nitrites were only present at undetectable concentrations. The relatively small nutrient concentrations in the water under ambient conditions (the majority were below the level of reliable detection) also demonstrate that nutrient treatments were independent.

A total of 1832 oysters were found on plates, and $99 \%$ of these were on the bottoms of plates. Recruitment of oysters on the bottoms of plates was almost exclusively to those made of PVC $(54.5 \%$ at low tidal levels, $44.3 \%$ at high tidal levels), with only $1.2 \%$ of oysters on wood plates at high tidal levels. At both tidal levels and for both sampling intervals, densities of recruits on PVC plates under elevated nutrient conditions were at least 3 times and significantly higher than those under ambient conditions (Fig. 1b,c, Table 1). There were few recruits on wood plates at high tidal levels and no significant differences between nutrient conditions (Fig. 1a, Table 1). Under both nutrient conditions, recruitment on PVC plates at low tidal levels was significantly greater when sampled at 2 wk intervals than when sampled once after $2 \mathrm{mo}$, whereas there was no significant difference between sampling intervals for plates at high tidal levels (Fig. 1, Table 1).

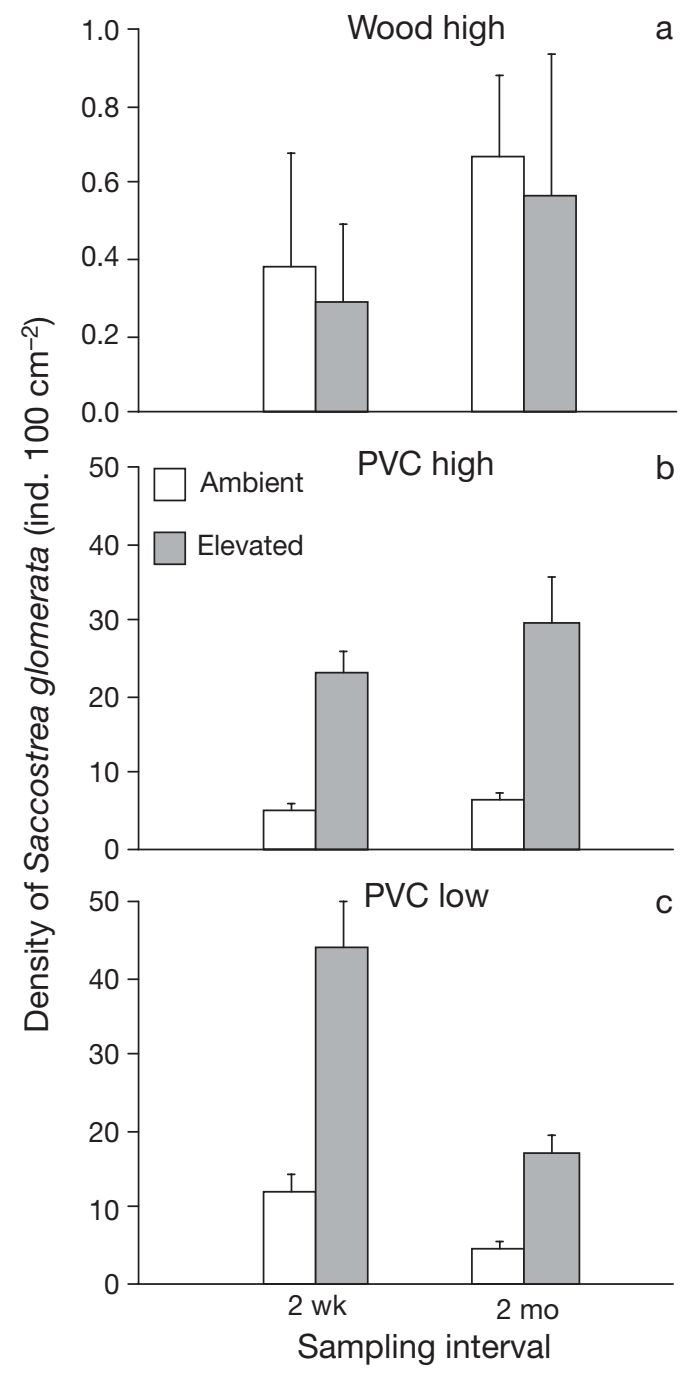

Fig. 1. Saccostrea glomerata. Mean $( \pm \mathrm{SE})$ density of recruits on (a) wood and (b) PVC plates at high tidal levels, and (c) PVC plates at low tidal levels under ambient and elevated nutrient conditions for sampling intervals of $2 \mathrm{wk}$ and $2 \mathrm{mo}$. Note differences in scales on $y$-axes

A total of 34253 recruits of the barnacle Hexaminius popeiana were found on plates, and $70.8 \%$ of these were on the bottoms of plates. Recruitment of $H$. popeiana on the bottoms of plates was almost exclusively to those at high tidal levels $(66.4 \%$ on wood plates, $32.6 \%$ on PVC plates), with only $1.0 \%$ of recruits on PVC plates at low tidal levels. Similar to oysters, for all plates sampled at 2 wk intervals, recruitment of $H$. popeiana was significantly greater - by at least $50 \%$ - under elevated than ambient nutrient conditions, with extremely large densities of recruits (almost $5 \mathrm{~cm}^{-2}$ ) on wood plates at high tidal levels (Fig. 2, Table 1). Despite these high densities there remained $>80 \%$ free space for settlement on all plates, even after 2 mo. 
Table 1. Saccostrea glomerata and Hexaminius popeiana. Top: Results of 2factor ANOVA for the effect of sampling interval ( $2 \mathrm{wk}$ or $2 \mathrm{mo}$ ), nutrients (ambient or elevated) and their interaction on recruitment on wood and PVC plates at high tidal levels (high) and PVC plates at low tidal levels (low). The df for sampling interval, nutrients and their interaction is 1 , and the $\mathrm{df}$ for the residual is 24 . Data were transformed to $\ln (x+1)$ prior to analysis to homogenize variances. Int $\times$ Nut $=$ interval $\times$ nutrients; NS $=$ not significant ${ }^{*}=p<0.05_{i}{ }^{* *}=p<$ $0.01 ;{ }^{* * *}=p<0.001$. Bottom: Results of SNK tests for significant interaction term (Interval $\times$ Nutrients) in ANOVA. $\mathrm{A}=$ ambient; $\mathrm{E}=$ elevated; $\mathrm{p}<0.05$

\begin{tabular}{|c|c|c|c|c|c|c|c|}
\hline \multirow{2}{*}{$\begin{array}{l}\text { ANOVA } \\
\text { Variable }\end{array}$} & \multicolumn{2}{|c|}{ Interval } & \multicolumn{2}{|c|}{ Nutrients } & \multicolumn{2}{|c|}{ Int $\times$ Nut } & \multirow{2}{*}{$\begin{array}{l}\text { Residual } \\
\text { MS }\end{array}$} \\
\hline & MS & $F$ & MS & $F$ & MS & F & \\
\hline \multicolumn{8}{|l|}{ S. glomerata } \\
\hline Wood high & 0.24 & $1.4 \mathrm{NS}$ & 0.05 & $0.3 \mathrm{NS}$ & 0.015 & $0.09 \mathrm{NS}$ & 0.17 \\
\hline PVC high & 0.40 & $2.1 \mathrm{NS}$ & 13.57 & $72.1^{* * *}$ & 0.021 & $0.11 \mathrm{NS}$ & 0.19 \\
\hline PVC low & 4.76 & $36.6^{* * *}$ & 10.49 & $80.5^{* * *}$ & 0.031 & $0.24 \mathrm{NS}$ & 0.13 \\
\hline \multicolumn{8}{|l|}{ H. popeiana } \\
\hline Wood high & 0.05 & $0.5 \mathrm{NS}$ & 0.27 & $2.7 \mathrm{NS}$ & 0.516 & $5.30^{*}$ & 0.10 \\
\hline PVC high & 58.10 & $181.9^{* * *}$ & 0.14 & $0.5 \mathrm{NS}$ & 4.075 & $12.76^{* *}$ & 0.32 \\
\hline PVC low & 2.44 & $6.4^{*}$ & 2.25 & $5.9^{*}$ & 0.006 & $0.02 \mathrm{NS}$ & 0.38 \\
\hline SNK tests & \multicolumn{4}{|c|}{ Interval } & \multicolumn{3}{|c|}{ Nutrients } \\
\hline Variable & & $2 \mathrm{wk}$ & $2 \mathrm{mo}$ & & Ambient & Elev & vated \\
\hline \multicolumn{8}{|l|}{ H. popeiana } \\
\hline Wood high & & $\mathrm{A}<\mathrm{E}$ & $A=E$ & & $2 \mathrm{wk}=2 \mathrm{mo}$ & $2 \mathrm{wk}$ & $>2 \mathrm{mo}$ \\
\hline PVC high & & $\mathrm{A}<\mathrm{E}$ & $A>E$ & & $2 \mathrm{wk}<2 \mathrm{mo}$ & $2 \mathrm{wk}$ & $<2 \mathrm{mo}$ \\
\hline
\end{tabular}

On plates left out for 2 mo, the effect of nutrients was variable: there was no significant difference in recruitment on wood plates at high tidal levels, significantly greater recruitment under ambient conditions on PVC plates at high tidal levels, and significantly greater recruitment under elevated conditions on PVC plates at low tidal levels (Fig. 2, Table 1). Densities of recruits on PVC plates at both tidal levels were significantly greater on plates left out over 2 mo compared to those replaced at 2 wk intervals (Fig. 2b,c, Table 1) and this difference was particularly striking at high tidal levels, where there was an order of magnitude difference in recruitment. In contrast, on wood plates at high tidal levels there were significantly fewer recruits on plates left out for 2 mo under elevated nutrient conditions, but an increase in recruitment under ambient conditions (Fig. 2c, Table 1). Interestingly, at high tidal levels, recruitment on wood plates was more than an order of magnitude greater than on PVC plates when sampled at $2 \mathrm{wk}$ intervals, whereas recruits were at similar densities on wood and PVC plates when sampled once after 2 mo (Fig. 2a,b) .

The only other sessile invertebrates to colonise plates were occasional barnacles, including the intertidal Elminius covertus and more typically subtidal Balanus spp. The snail Bembicium auratum and the limpet Patelloida mimula were occasionally observed on plates, but these grazers were few in number and their presence was not obviously related to the addition of fertiliser. Similarly, small amounts of filamentous green algae colonised most plates left out for 2 mo, regardless of nutrient load.

\section{DISCUSSION}

Nutrient enrichment dramatically affected the recruitment of oysters and barnacles, which are dominant occupiers of space and provide habitat for other organisms living on trunks of trees in temperate mangrove forests in New South Wales, Australia (Ross \& Underwood 1997, Minchinton \& Ross 1999). Recruitment of both the oyster Saccostrea glomerata (for both sampling intervals) and the barnacle Hexaminius popeiana (for $2 \mathrm{wk}$ sampling intervals only) was substantially increased in the presence of elevated nutrients. This enhanced recruitment may be due to increased settlement or reduced mortality of larvae while plates were in the water and before recruits were counted (Minchinton \& Scheibling 1993a). Moreover, increased settlement may be a direct response by larvae to the nutrients in the water column or an indirect response to environmental conditions related to nutrient enrichment, such as biofilms (Fitt et al. 1990, Pawlik 1992, Tamburri et al. 1992, Anderson 1996, Faimali et al. 2004). Although this experiment cannot distinguish between these alternative explanations, some are more plausible than others.

The positive response of oysters to nutrients was consistent for both sampling intervals, indicating that longer-term patterns of recruitment are likely to be similar to those of larvae at settlement. Indeed, despite considerable mortality of settlers on PVC plates at low tidal levels, the positive influence of nutrients on oyster recruitment was maintained over 2 mo, suggesting that the positive effects of nutrients on settlement are greater than any negative effects on postsettlement mortality. Similarly, the barnacle Hexaminius popeiana recruited in greater densities under elevated nutrient conditions on fresh plates exchanged at $2 \mathrm{wk}$ intervals. This evidence suggests that nutrients in the water column are influencing the settlement of barnacles and oyster larvae. Alternatively, nutrients could be affecting environmental conditions on the plates and these changes might indirectly account for the observed settlement patterns. For example, grazing snails have been shown to facilitate the recruitment of Saccostrea glomerata by removing algae (Anderson \& Underwood 1997, Anderson 1999), but few grazers were found on plates. Indeed, there were no obvious differences in algae between plates with elevated and ambient nutrient levels and, what is more, algae have been shown to have no effect on the recruitment of Hexaminius spp. 


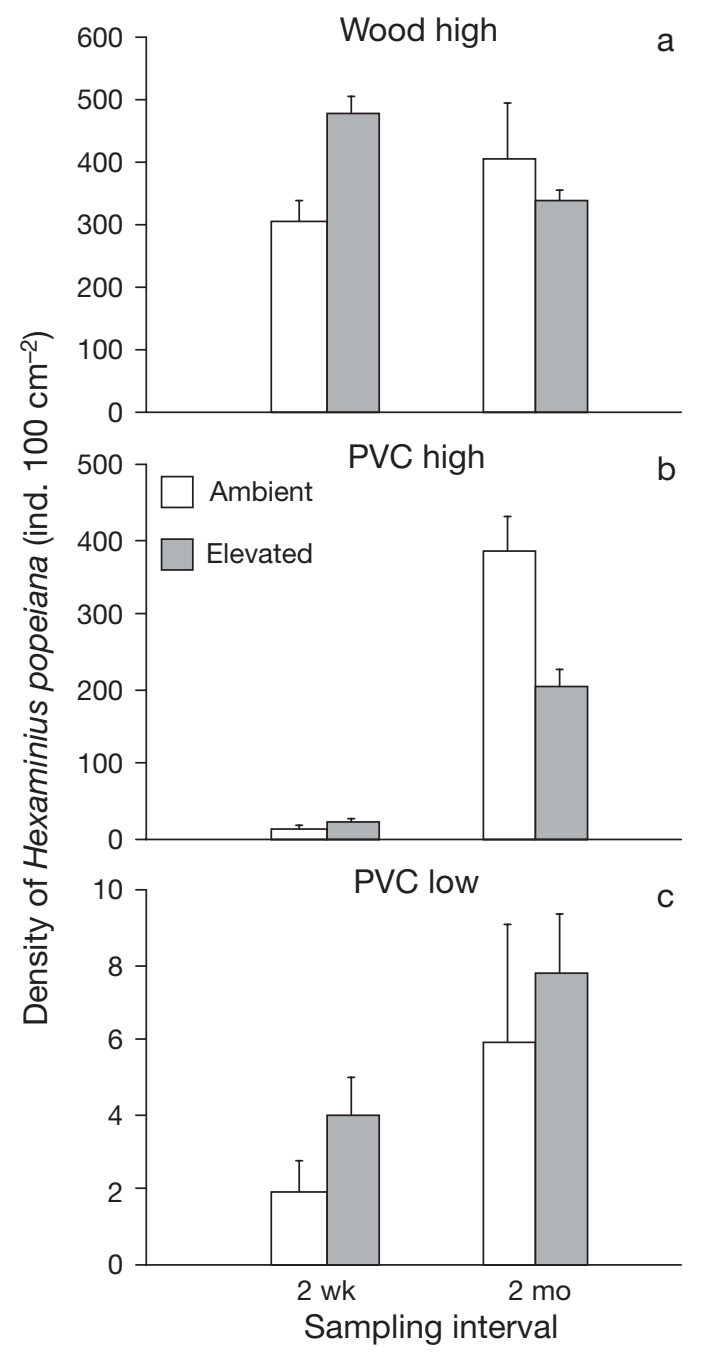

Fig. 2. Hexaminius popeiana. Mean $( \pm \mathrm{SE})$ density of recruits on (a) wood and (b) PVC plates at high tidal levels, and (c) PVC plates at low tidal levels under ambient and elevated nutrient conditions for sampling intervals of $2 \mathrm{wk}$ and $2 \mathrm{mo}$.

Note differences in scales on $y$-axes

and only small negative effects on $S$. glomerata, which could not account for the differences here (Anderson \& Underwood 1997, Anderson 1999).

More likely, nutrients might be acting as settlement cues for the presence of conspecific individuals. Indeed, other investigators have found that Hexaminius popeiana responds positively to conspecific adults (Coates \& McKillup 1995, see also Ross 2001); similarly, the larvae of several oyster species settle gregariously (Bayne 1969, Hidu \& Haskin 1971). Moreover, several species of oysters have been shown to respond positively to nutrients, particularly ammonia, which is produced in relatively high concentrations by conspecific adults (Coon et al. 1990, Fitt et al. 1990, Fitt \& Coon 1992). There is indeed evidence that bases, such as ammonia and calcium hydroxide, may stimu- late settlement of oyster larvae, including Saccostrea glomerata (e.g. Coon et al. 1990, Anderson 1996). Therefore. nutrients might act as a cue promoting the settlement of oyster, and perhaps barnacle, larvae.

Importantly, this positive influence of nutrients on oyster recruitment occurred only $10 \mathrm{~s}$ of $\mathrm{cm}$ away from large densities of oysters on the mangrove trees and pneumatophores, indicating that nutrients enhanced recruitment above any effects that might have been due to conspecific cues alone (Fitt \& Coon 1992). We speculate that nutrients might provide a general environmental cue for sessile or sedentary benthic marine invertebrates, potentially indicating the presence of conspecific individuals, biofilms or a benthic species assemblage and habitat suitable for settlement (Coon et al. 1990, Fitt \& Coon 1992, Tamburri et al. 1992). These results suggest that, if anthropogenic nutrient enrichment mimics natural settlement cues of oysters, then larvae might be stimulated to settle in areas without conspecific adults, and away from suitable habitat, for subsequent growth and reproduction, which might have deleterious consequences for local populations.

In contrast to oysters, the initial positive response of the barnacle Hexaminius popeiana to nutrients at high tidal levels was not maintained as recruits accumulated on plates over time, and after 2 mo recruitment was greater under ambient conditions (except at low tidal heights where there were only small densities of recruits). These opposing patterns of recruitment for $H$. popeiana over time suggest that plates with nutrients became relatively less attractive to settlers or had higher settler mortality than those under ambient conditions. On wood plates at high tidal levels, patterns of recruitment support the explanation for increased postsettlement mortality, because plates with nutrients left out for 2 mo had fewer recruits than those replaced at 2 wk intervals, whereas the reverse was true for plates under ambient conditions. On PVC plates at high tidal levels, recruitment was more than an order of magnitude greater on plates left out for 2 mo compared to those replaced every $2 \mathrm{wk}$, suggesting that all plates, regardless of nutrient levels, became more attractive to larvae as they accumulated conspecific individuals and a benthic species assemblage (Coates \& McKillup 1995). This increase in recruitment after 2 mo was, however, twice as high under ambient than elevated nutrient conditions, indicating that on this material nutrients were having a negative influence on recruitment of $H$. popeiana relative to ambient conditions. These results suggest that nutrients might provide a positive cue for settlement on fresh PVC plates with relatively few conspecific individuals and an undeveloped benthic species assemblage, but have negative effects on recruitment as the benthic species assemblage develops over time. 
What accounts for this difference in the effect of nutrients on recruitment of Hexaminius popeiana between sampling intervals is not known, but it is unlikely that these patterns of recruitment were affected by pre-emptive or density-dependent competition, or by dislodgement or predation of recent settlers by other organisms. The only sessile invertebrates to colonise plates were barnacles and oysters and, even after $2 \mathrm{mo}$, there was $>80 \%$ free space for settlement on all plates. The potential for differential bulldozing of recent settlers by the snail Bembicium auratum and the limpet Patelloida mimula, which are common and abundant in these forests (Underwood \& Barrett 1990, Minchinton \& Ross 1999), is unlikely because few snails and limpets were found on plates (see also Anderson \& Underwood 1997, Anderson 1999). The activities of potential predators at high tide, such as crabs and fish, were not observed, but they are unlikely to prey on small, recently settled individuals. Therefore, we speculate that these variable effects of nutrients on recruitment of the barnacle $H$. popeiana over time are due to a combination of (1) larvae switching their behaviour towards nutrients from positive to negative as conspecific individuals and the benthic species assemblage accumulate (Minchinton \& Scheibling 1993b) and (2) increased postsettlement mortality in the presence of nutrients.

Although it was not the objective of the present study to compare recruitment between the different materials of the plates, we must highlight the striking differences in recruitment between wood and PVC for both Saccostrea glomerata and Hexaminius popeiana at high tidal levels (see also Anderson \& Underwood 1994). Such results reinforce the argument that the design of recruitment studies must carefully consider how the response (settlement and early mortality) of larvae to the materials of settlement plates (or differences in the composition of natural substrata) might vary with the development of biofilms and the benthic assemblage over time (e.g. Faimali et al. 2004), producing complex interactions and making it difficult to determine the causal factors affecting variations in recruitment (e.g. Anderson \& Underwood 1994).

The exact element or compound responsible for differences in recruitment under elevated nutrient conditions could not be identified in this study. Orthophosphates, nitrates and particularly ammonia were all in greater concentrations under elevated nutrient treatments, and these concentrations are within the range of those sampled in waters of the urbanised catchment of Sydney, Australia (Sydney Water Corporation 2005, see also Clarke 1985). Because ammonia has been shown to affect settlement and recruitment of benthic invertebrates such as oysters in past studies (e.g. Coon et al. 1990, Fitt \& Coon 1992), the dramatically in- creased availability of this compound is likely to also be significant here. Importantly, other elements might have been incidentally increased through the experimental addition of nutrients. For example, excess potassium ions have been shown to induce, as well as inhibit, settlement of marine invertebrates, including barnacles and Saccostrea glomerata (Nell \& Holliday 1986, Rittschof et al. 1986, Kang et al. 2004), and thus might also be contributing to observed effects. While it is a significant next step to determine which nutrients (or associated chemicals) might influence settlement and early mortality of larvae, the cocktail of nutrients manipulated here is representative of those being loaded at increasing levels into coastal waters of urban catchments (Valiela et al. 1997, Carpenter et al. 1998).

Oysters and barnacles are the dominant occupiers of space on temperate mangrove trees and, therefore, increased nutrient loads to mangrove forests might affect the population dynamics of these species, as well as those that depend on them for food or habitat. For example, if the recruitment of oysters is positively affected and that of barnacles negatively affected by nutrients in the long-term, then species assemblages on trees might become increasingly dominated by oysters. How nutrient enrichment influences the dynamics of populations and species assemblages in marine benthic habitats remains largely unknown, but if nutrients significantly affect recruitment, which is a key process structuring marine communities, then their effects are likely to be substantial. A major difficulty with this research is that substantial spatial and temporal variability of nutrient inputs to coastal waterways makes it difficult to link unambiguously changes to species assemblages with varying loads. Future studies will need to include longterm observations of changes to key habitat-forming species and species assemblages at multiple places as nutrient loads vary, coupled with an understanding of the individual response of species to particular nutrients in field and laboratory experiments.

Acknowledgements. We thank J. Larsen for help in the field. Comments on the research and logistical support were provided by D. J. Ayre, T. P. Lynch, M. O'Donnell, R. J. West, P. M. Ross, and J. C. Simpson. The Oyster Farmers Association of New South Wales generously donated the oyster slats.

\section{LITERATURE CITED}

American Public Health Association (1998) Standard methods for the examination of water and wastewater, 20th edn. American Public Health Association, American Water Works Association and Water Environment Federation, Washington, DC

Anderson MJ (1996) A chemical cue induces settlement of Sydney rock oysters, Saccostrea commercialis in the laboratory and in the field. Biol Bull 190:350-358 
Anderson MJ (1999) Distinguishing direct from indirect effects of grazers in intertidal estuarine assemblages. J Exp Mar Biol Ecol 234:199-218

Anderson MJ, Underwood AJ (1994) Effects of substratum on the recruitment and development of an intertidal estuarine fouling assemblage. J Exp Mar Biol Ecol 184:217-236

Anderson MJ, Underwood AJ (1997) Effects of gastropod grazers on recruitment and succession of an estuarine assemblage: a multivariate and univariate approach. Oecologia 109:442-453

Bassim KM, Sammarco PW (2003) Effects of temperature and ammonium on larval development and survivorship in a scleractinian coral (Diploria strigosa). Mar Biol 142: 241-252

Bayne BL (1969) The gregarious behaviour of the larvae of Ostrea edulis L. at settlement. J Mar Biol Assoc UK 49: 327-356

Boto KG, Wellington JT (1983) Phosphorus and nitrogen nutritional status of a northern Australian mangrove forest. Mar Ecol Prog Ser 11:63-69

Burke RD (1983) The induction of metamorphosis of marine invertebrate larvae: stimulus and response. Can J Zool 61: 1701-1719

Caley MJ, Carr MH, Hixon MA, Hughes TP, Jones GP, Menge BA (1996) Recruitment and the local dynamics of open marine populations. Annu Rev Ecol Syst 27:477-500

Carpenter SR, Caraco NF, Correll DL, Howarth RW, Sharpley AN, Smith VH (1998) Nonpoint pollution of surface waters with phosphorus and nitrogen. Ecol Appl 8:559-566

Clarke PJ (1985) Nitrogen pools and soil characteristics of a temperate estuarine wetland in eastern Australia. Aquat Bot 23:275-290

Coates M, McKillup SC (1995) Role of recruitment and growth in determining the upper limit of distribution of the intertidal barnacle Hexaminius popeiana. Mar Freshw Res 46:1065-1070

Coon SL, Walch M, Fitt WK, Weiner RM, Bonar DB (1990) Ammonia induces settlement behavior in oyster larvae. Biol Bull 179:297-303

Cox EF, Ward S (2002) Impact of elevated ammonium on reproduction in two Hawaiian scleractinian corals with different life history patterns. Mar Poll Bull 44:1230-1235

Faimali M, Garaventa F, Terlizzi A, Chiantore M, CattaneoVietti R (2004) The interplay of substrate nature and biofilm formation in regulating Balanus amphitrite Darwin, 1954 larval settlement. J Exp Mar Biol Ecol 306:37-50

Fitt WK, Coon SL (1992) Evidence for ammonia as a natural cue for recruitment of oyster larvae to oyster beds in a Georgia salt marsh. Biol Bull 182:401-408

Fitt WK, Coon SL, Walch M, Weiner RM, Colwell RR, Bonar DB (1990) Settlement behaviour and metamorphosis of oyster larvae (Crassostrea gigas) in response to bacterial supernatants. Mar Biol 106:389-394

Hall SJ, Gray SA, Hammett ZL (2000) Biodiversity-productivity relations: an experimental evaluation of mechanisms. Oecologia 122:545-555

Hidu H, Haskin HH (1971) Setting of the American oyster related to environmental factors and larval behaviour. Proc Nat Shellfish Assoc 61:35-50

Jara VC, Miyamoto HES, da Gama BAP, Molis M, Wahl M, Pereira RC (2006) Limited evidence of interactive disturbance and nutrient effects on the diversity of macrobenthic assemblages. Mar Ecol Prog Ser 308:37-48

Kang KH, Kim BH, Kim JM (2004) Induction of larval settlement and metamorphosis of the abalone, Haliotis discus hannai larvae using bromomethane and potassium chloride. Aquaculture 230:249-259
Keough MJ, Downes BJ (1982) Recruitment of marine invertebrates: the role of active larval choice and early mortality. Oecologia 54:348-352

Koop K, Booth D, Broadbents A, Brodie J and others (2001) ENCORE: The effect of nutrient enrichment on coral reefs. Synthesis of results and conclusions. Mar Poll Bull 42:91-120

Littler MM, Murray SN (1975) Impact of sewage on the distribution, abundance and community structure of rocky intertidal macro-organisms. Mar Biol 30:277-291

McClanahan TR, Cokos BA, Sala E (2002) Algal growth and species composition under experimental control of herbivory, phosphorus and coral abundance in Glovers Reef, Belize. Mar Poll Bull 44:441-451

Minchinton TE, Bertness MD (2003) Disturbance-mediated competition and the spread of Phragmites australis in a coastal marsh. Ecol Appl 13:1400-1416

Minchinton TE, Ross PM (1999) Oysters as habitat for limpets in a temperate mangrove forest. Aust J Ecol 24:157-170

Minchinton TE, Scheibling RE (1991) The influence of larval supply and settlement on the population structure of barnacles. Ecology 72:1867-1879

Minchinton TE, Scheibling RE (1993a) Variations in sampling procedure and frequency affect estimates of recruitment of barnacles. Mar Ecol Prog Ser 99:83-88

Minchinton TE, Scheibling RE (1993b) Free space availability and larval substratum selection as determinants of barnacle population structure in a developing rocky intertidal community. Mar Ecol Prog Ser 95:233-244

Morris L, Keough MJ (2003) Variation in the response of intertidal infaunal invertebrates to nutrient additions: field manipulations at two sites within Port Phillip Bay, Australia. Mar Ecol Prog Ser 250:35-49

Nell JA, Holliday JE (1986) Effects of potassium and copper on the settling rate of Sydney rock oyster (Saccostrea commercialis) larvae. Aquaculture 58:26-267

Pawlik JR (1992) Chemical ecology of the settlement of benthic marine invertebrates. Oceanogr Mar Biol Annu Rev 30:273-335

Renaud PE, Syster DA, Ambrose WG Jr (1999) Recruitment patterns of continental shelf benthos off North Carolina, USA: effects of sediment enrichment and impact on community structure. J Exp Mar Biol Ecol 237:89-106

Rittschof D, Maki J, Mitchell R (1986) Ion and neuropharmacological studies of barnacle settlement. Neth J Sea Res 20:269-275

Ross PM (1993) The ecology of barnacles in temperate mangrove forests. PhD thesis, The University of Sydney

Ross PM (1996) Differences in morphology and reproduction of the barnacles Elminius covertus and Hexaminius spp. from mangrove forests in the Sydney region of New South Wales. Mar Freshw Res 47:715-721

Ross PM (2001) Larval supply, settlement and survival of barnacles in a temperate mangrove forest. Mar Ecol Prog Ser 215:237-249

Ross PM, Underwood AJ (1997) The distribution and abundance of barnacles in a mangrove forest. Aust J Ecol 22: $37-47$

Russell BD, Connell SD (2005) A novel interaction between nutrients and grazers alters relative dominance of marine habitats. Mar Ecol Prog Ser 289:5-11

Sydney Water Corporation (2005) Environmental Indicators Compliance Report, Vol 2, Sydney Water Annual Report 2005. Sydney Water Corporation, Sydney

Tamburri MN, Zimmer-Faust RK, Tamplin ML (1992) Natural sources and properties of chemical inducers mediating settlement of oyster larvae: A re-examination. Biol Bull 183:327-338 
Underwood AJ, Anderson MJ (1994) Seasonal and temporal aspects of recruitment and succession in an intertidal estuarine fouling assemblage. J Mar Biol Assoc UK 74:563-584

Underwood AJ, Barrett G (1990) Experiments on the influence of oysters on the distribution, abundance and sizes of the gastropod Bembicium auratum in a mangrove swamp in New South Wales, Australia. J Exp Mar Biol Ecol 137: 25-45

Valiela I, Teal JM (1974) Nutrient limitation in salt marsh veg-

Editorial responsibility: Pei-Yuan Qian, Kowloon, Hong Kong SAR etation. In: Reimold RJ, Queen WH (eds) Ecology of halophytes. Academic Press, New York, p 547-563

Valiela I, Collins G, Kremer J, Lajtha K and others (1997) Nitrogen loading from coastal watersheds to receiving estuaries: new method and application. Ecol Appl 7:358-380

Ward S, Harrison PL (1997) The effects of elevated nutrient levels on settlement of coral larvae during the ENCORE experiment; Great Barrier Reef, Australia. Proc 8th Int Coral Reef Symp, Panama 1:891-896

Submitted: July 10, 2006; Accepted: July 26, 2007

Proofs received from author(s): January 21, 2008 